\title{
Measuring rheological properties of cement pastes: most common techniques, procedures and challenges
}

\author{
Dimitri Feys $^{\mathrm{a}^{*}}$, Rolands Cepuritis $^{\mathrm{b}}$, Stefan Jacobsen ${ }^{\mathrm{b}}$, Karel Lesage $^{\mathrm{c}}$, Egor Secrieru $^{\mathrm{d}}$, Ammar Yahia $^{\mathrm{e}}$

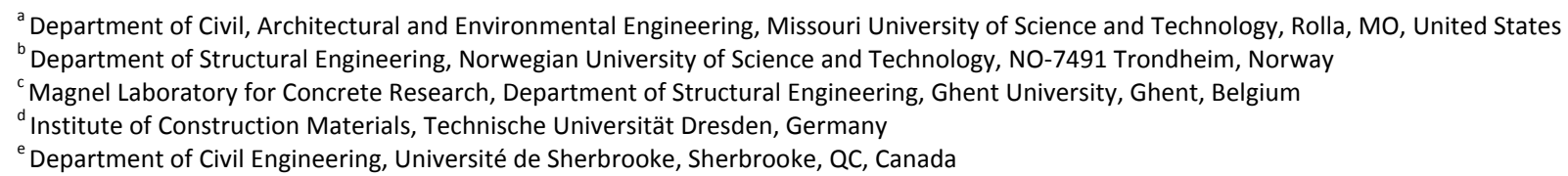

Received: 29 November 2017 / Accepted: 25 December 2017 / Published online: 31 December 2017

(C) The Author(s) 2017. This article is published with open access and licensed under a Creative Commons Attribution 4.0 International License.

\begin{abstract}
The science of rheology is increasingly used to describe the properties of fresh cement paste. Compared to standard workability tests, rheological properties allow for more fundamental investigation, more precise phenomenological description of flow properties and serve as input for numerical simulations. Standard commercially available rheometers are typically used to perform those measurements. However, the results of the measurement depend on the geometry, testing procedure and a number of potential artefacts. This technical letter describes the most common techniques and procedures used to assess the rheological properties of cement paste, as well as challenges during measurements and actions to counter these challenges.
\end{abstract}

Keywords: Rheology; Cement paste; Measuring techniques; Experimental errors; Rheometer

\section{Introduction}

Measuring rheological properties of cement pastes is a more fundamental way of assessing fresh properties, compared to standard workability tests. However, measuring the rheological properties of these materials is not a straightforward task, and substantial care must be taken prior, during and after the measurements [1]. There are a number of difficulties arising when measuring on cement pastes: (i) The pastes contain a large number of particles, with sizes around the boundary between colloidal and noncolloidal particles [2-4]. The colloidal particles are subjected to inter-particle interactions, such as Van der Waals dispersion and electrostatic repulsion forces [3]. (ii) The pastes undergo a chemical reaction with time [2, 4-5], changing the rheological properties. (iii) A majority of the developed chemical admixtures are designed to either change the properties of the suspending medium, the interaction forces between the particles, or to change the rate at which the chemical reaction occurs [6]. As such, cement pastes are typically thixotropic materials with a yield stress and varying rheological properties over time. In some cases, non-linear rheological behavior can also be observed [7-9].

\footnotetext{
* Corresponding author: Dimitri Feys, E-mail: feysd@mst.edu
}

This technical letter informs cement paste rheologists on the most common measuring geometries, testing procedures, as well as the encountered challenges. The properties focused on are the flow curves, thixotropic and visco-elastic behavior. For pastes with a yield stress in the order of $10^{3} \mathrm{~Pa}$ or higher, different principles than the concepts discussed in this letter apply [10-12]. This letter also only discusses cement pastes, as RILEM TC 266 is preparing a state-of-theart report on measuring the rheological properties of mortar and concrete. It should be noted that this technical letter does not reflect the opinion of the entire committee, but it is rather the vision of the authors, based on their experiences and literature.

\section{Measuring geometries}

In this section, the geometries most frequently used by cement paste rheologists are listed, with their advantages and disadvantages. It should be noted that all of them show one or more general challenges that are separately treated in section 4. 


\subsection{Concentric cylinders geometry}

The concentric cylinders geometry (also referred to as "bobin-cup", "coaxial cylinders" or "Couette cell") often consists of a static cylindrical cup and a concentric rotatable cylinder [13-16] (or vice-versa), as drawn in Fig. 1. The cylinder is immersed in the partially filled cup so that the paste levels at least with the top surface of the cylinder. Over the gap width $\left(R_{0}-R_{i}\right)$ and over the length $L$, there now appears a tangential velocity field $\left(v_{\theta}\right)$. Depending on the system settings, either stress or shear rate can be applied. To that end, one of the two cylinders also needs connection with a torque sensor that will deliver the input for stress calculations. Often, both rotation and torque measurement are integrated in the motor to which the inner cylinder is attached.

In the case of a rotating cylindrical bob, $v_{\theta}=R_{i} \Omega$ at the surface of the inner cylinder and $v_{\theta}=0$ at the surface of the inner cup wall. The shear stress $(\tau)$ can then be calculated from the registered torque (T) following Eq. 1 [1316], typically evaluated at the inner cylinder $\left(r=R_{i}\right)$. The average shear rate $(\dot{\gamma})$ is often calculated from Eq. 2, valid for small gaps $\left(\frac{R_{i}}{R_{0}} \sim 0.99\right)$ [13-16]. Eq. 2 implies a uniform velocity field which is not always the case in practice. Hence, for larger gaps, more complex transformation formulas need to be applied, such as Eq. 3, in which the slope of the torque $(T)$ - angular velocity $(\Omega)$ relationship in a double log diagram appears [13-16]. Based on the authors' experience, the gap widths for paste in cylinder-like geometries vary between 1 and $3 \mathrm{~mm}$, which in most cases do not fulfill the small gap condition.

$\tau(r)=\frac{T}{2 \pi \cdot L r^{2}}$

$\dot{\gamma}=\frac{\Omega R_{0}}{R_{0}-R_{i}}$

$\dot{\gamma}_{R_{i}}=\frac{2 \Omega}{n\left(1-\left({ }^{R_{i}} / R_{o}\right)^{2 / n}\right)} \quad$ with $\quad n=\frac{\operatorname{dln}(T)}{\operatorname{dln}(\Omega)}$

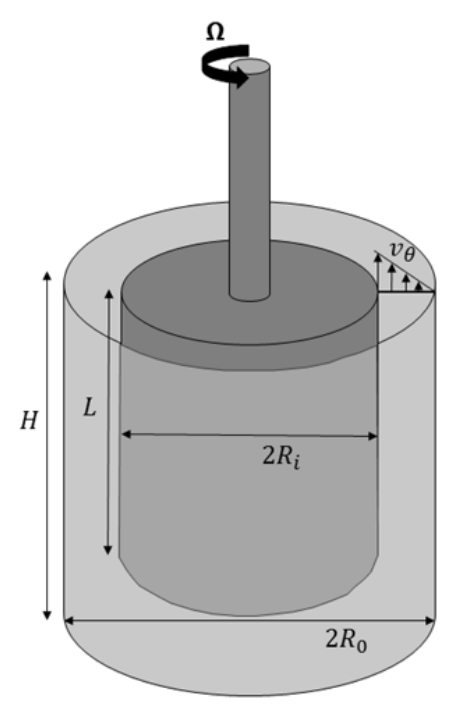

Figure 1. Concentric cylinders geometry.
The advantages of the concentric cylinders geometry are: (1) For really small gaps $\left(\frac{R_{i}}{R_{0}} \sim 0.99\right)$, there is constant shear rate, but a wide gap geometry also allows larger particles to be used, (2) the large measurement surface provides relatively good accuracy (steady laminar flow), (3) settling materials can be measured reasonably well [17] (see section 4.5) and (4) any surface drying has a relatively limited effect compared to other geometries. Particular disadvantages of the concentric cylinders for cement paste investigation are: (1) The fixed gap width, unless equipment costs are not an issue, (2) the risk of slippage and plug flow, which are further elaborated in section 4 and (3) the end effects at the bottom and the top of the cylinder that need to be reduced or corrected for [18]. There are similar geometries like the conic cylinder or the recessed bottom cylinder that reduce these end effects.

The vane-cup geometry shows high resemblance to the measuring mechanism of the concentric cylinders geometry. In principle, the vane replaces the inner cylinder and is expected to collect paste in between its blades so that a virtual "cylinder of paste" rotates alongside the paste volume in the gap. For an increasing number of vane blades, the circumferential polygon approaches the circle of the inner cylinder. Calculation of the rheological properties occurs in a way analogous to the concentric cylinders. Literature shows that the vane is less likely to demonstrate wall-slip than a cylindrical bob would do in the same paste [19]. All other concentric cylinders advantages and disadvantages remain. For the end effects no easy physical solution exists, but experimental countermeasures can be considered [20].

\subsection{Parallel plate geometry}

The parallel plate geometry (Fig. 2) typically consists of two parallel circular plates with radius $R$ separated by a gap width $h$ in which the sample is contained by surface tension [13-16]. Usually the upper plate is lowered upon the deposited sample, squeezing it until the preset gap width is reached. Paste excesses are subsequently trimmed manually. Literature values for the gap width are between 700 and $1000 \mu \mathrm{m}$, although it is still not clear what would make a value appropriate [21]. During the measurement, the upper plate rotates to create a shear velocity profile as shown in Fig. 2. Due to the vertical dimension, the shear rate is not constant over the radius. It depends on the considered height in the squeezed sample and is calculated using Eq. 4 [13]. The shear stress can be calculated using Eq. 5, and is dependent on the shear rate [13-16].

$$
\begin{aligned}
& \dot{\gamma}(r)=\frac{\Omega r}{h} \\
& \tau(r)=\frac{T}{2 \pi \cdot r^{3}}\left[3+\frac{d \ln T}{d \ln \dot{\gamma}_{R}}\right]
\end{aligned}
$$

The advantages of the parallel plate geometry are: (1) a steady laminar flow and (2) shear rate and strain can be altered by changing the gap width $(h)$. The disadvantages are: (1) a non-homogeneous flow field, (2) settling can be a problem with the upper plate rotating on the fluid only, (3) surface drying at the outer sample rim and (4) the loading 
procedure of the sample is considerably more sensitive to system settings [22]. As an alternative to the parallel plates, a cone and plate geometry can be suggested. This has the particular advantage that the shear rate is homogenously distributed in contrast to the parallel plates [13]. However, below the central downwards facing top of the cone, the gap width is too small for cementitious particles to flow easily causing blockages and stress peaks.

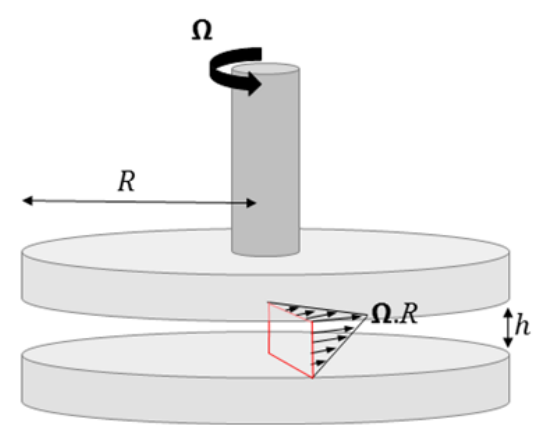

Figure 2. Parallel plate geometry.

\subsection{Other geometries}

The popular types of geometries above illustrate the flaws and weaknesses of geometries that are also used by rheologists in other fields [16]. The creation of a laminar uniform flow field is the main challenge to allow proper calculation of the true shear stress and shear rate. A number of customized geometries is being promoted, e.g. with protruding lamellas, anchor shapes, helical ribbon combinations, etc., that are said to provide more uniform flow. For all these geometries, the shear stress and shear rate are correlated to the measured torque and to the number of revolutions by regression analysis. The resulting fitting parameters do not necessarily incorporate the actual physical shearing of suspended particles. However, these systems are still valuable when making relative comparisons in-between a batch of samples of similar composition.

\section{Measuring procedures}

The emphasis is now placed on the rheological characterisation of cement paste behaviour in rotational and oscillatory tests as mostly used methods. Basic approaches are provided with respect to measuring cement paste properties and performing rheological tests.

\subsection{General approach}

Cement pastes are yield stress fluids [2, 3, 23], meaning that the material flow is initiated as soon as the applied stress exceeds the yield stress. Depending on the mixture proportioning and applied shear rate or shear stress, cement pastes may display shear thinning or shear thickening behaviour [2, 7-9]. The testing procedure is chosen based on the investigated material properties, i.e., steady flow, thixotropic or visco-elastic behaviour in rotational or oscillatory tests. Initially, the material response towards deformation is analysed in a series of preliminary tests. Consequently, the specific testing regime, e.g. the magnitude of the applied shear strain, shear stress, shear rate or frequency are defined. The rheological measurements are generally performed under constant temperature and relative humidity, unless these are parameters under investigation.

\subsection{Steady flow properties}

The steady flow properties of cement-pastes refer to viscosity and yield stress by means of so-called flow curves, as seen in Fig. 3. The test is either performed in steps with a couple of seconds for each shear stress or shear rate increment, or in a linear fashion. Generally, either the up and down parts of the loop curve are completed, or solely the decreasing part is imposed. The downward branch is used to calculate the rheological properties depending on the applied model [24] (see section 4.1 for reasoning). Although various empirical models have been used to fit the flow curve measurements [25-29], the Bingham (Eq. 6) and Herschel-Bulkley (Eq. 7) models are most widely used to estimate the rheological parameters. However, these estimates are highly dependent on the accuracy of the experimental data and rheometer specifications.

$$
\begin{aligned}
& \tau=\tau_{0}+\mu_{p} \dot{\gamma} \\
& \tau=\tau_{0}+K \dot{\gamma}^{n}
\end{aligned}
$$

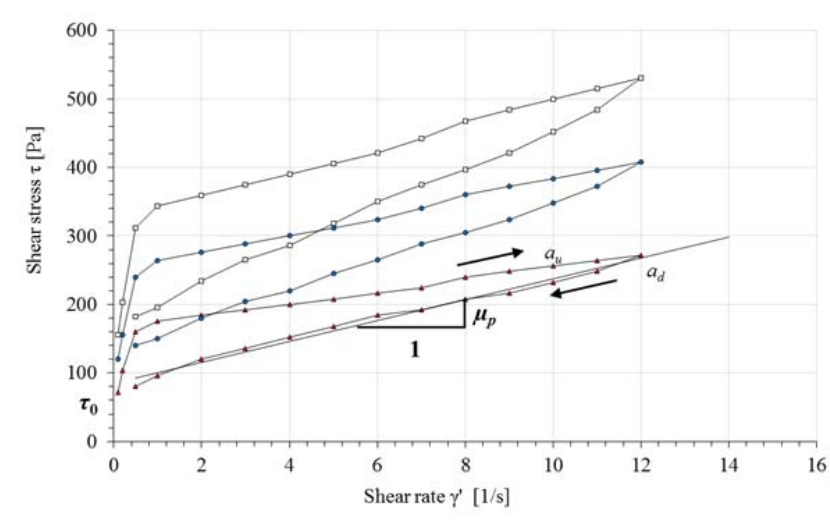

Figure 3. Shear stress versus shear rate hysteresis cycles at different material age showing the ascending $a_{u}$ and descending $a_{d}$ branches and a linear approximation of the descending branch to determine the Bingham parameters yield stress $\tau_{0}$ and plastic viscosity $\mu_{p}$.

\subsection{Thixotropic behaviour}

Thixotropy is generally associated with a physico-chemical phenomenon [30-31] causing changes in shear stress at constant shear rate, or vice versa. However, flocculation and hydration occur simultaneously, so attributing build-up or breakdown solely to one of these phenomena is not straightforward. If build-up is reversible, thixotropic behaviour is observed. Permanent changes in rheological properties with time are defined as workability loss. Numerous techniques and strategies can be employed to determine the thixotropy or structural build-up (combining thixotropy with workability loss), of which the hysteresis 
loops and static yield stress measurements are deemed most common in literature.

The hysteresis loops shown in Fig. 3 are often applied as preliminary attempts to "quantify" the thixotropy of the material [14, 32-33]. The entire area in between the up and down curves, and their evolution with time, is one way to assess thixotropy. Other approaches only consider a part of the area in between the up and down curves for the thixotropic index [34]. However, one must address such results rather as subjective due to high risk of inaccurate interpretation, since the area and the shape of the hysteresis loops very much depend on the testing parameters [2, 3536].

An alternative technique is to apply an increasing shear strain at low or very low shear rates in the range between $10^{-1}$ and $10^{-3} \mathrm{~s}^{-1}$. The result is the static yield stress $\tau_{0 s}$, that corresponds to a critical shear strain $\gamma_{c}$ as parameter for the thixotropic build-up of the material [37], as shown in Figure 4. When plotting the static yield stress values as a function of resting time, the slope $\left(A_{\text {thix }}\right)$ is a strong indicator for structural buildup [30, 32].

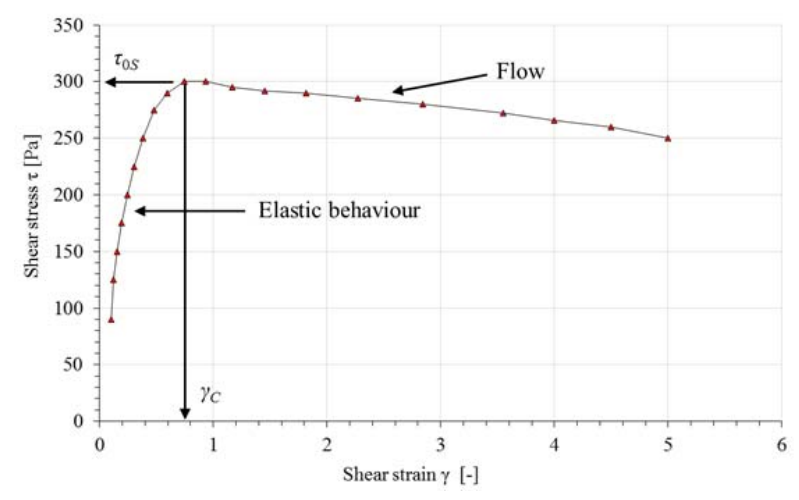

Figure 4. Determination of static yield stress $\tau_{0 \mathrm{~s}}$ in a shear strain test.

\subsection{Visco-elasticity}

Oscillatory measurements represent an effective method to determine and describe the linear (LVE) and nonlinear viscoelastic (NVE) behaviour of cement pastes [38-40], by monitoring the evolution of the complex modulus $\mathrm{G}^{*}=$ $(\tau(t) / \gamma(t))$. The storage modulus $G^{\prime}=(\tau / \gamma) \cdot \cos \delta$ (elastic response), loss modulus $G^{\prime \prime}=(\tau / \gamma) \cdot \sin \delta$ (viscous response) and phase angle $\delta\left(\tan \delta=G^{\prime \prime} / G^{\prime}\right)$ can be determined from the oscillations (Fig. 5).

Oscillatory tests, typically performed at a frequency of $1 \mathrm{~Hz}$ $[31,37,41]$, provide information about the amount of elastic energy and viscous dissipation during material flow. Stress or strain amplitude sweeps are generally used to determine the critical strain or stress of cement paste, which generally corresponds to the end of the LVE or to the onset of flow. The critical strain is typically of an order of $10^{-4}[31,37,41$ 43]. In the LVE domain, the evolution of $\mathrm{G}^{\prime}$ with time can serve as a measurement of structural build-up [31, 37]. However, exceeding the critical strain induces non-linear visco-elastic behaviour, significantly complicating the analysis [40].

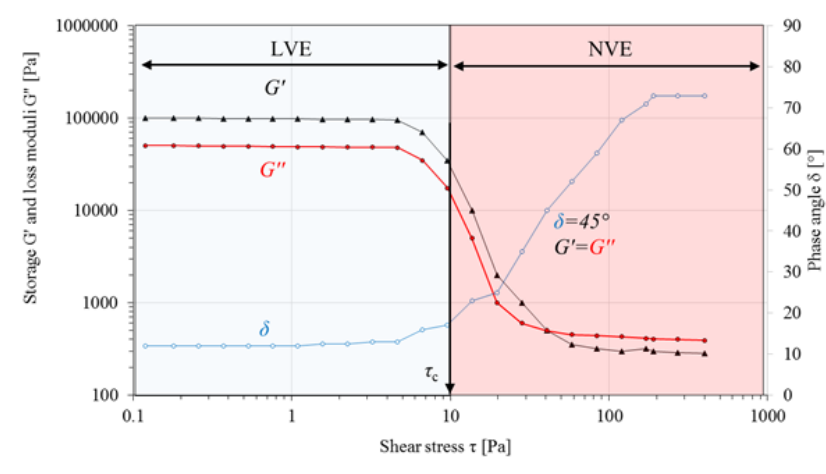

Figure 5. Shear elastic modulus as a function of shear stress. The oscillation frequency is $1 \mathrm{~Hz}$ and the shear stress is increased from 0.1 to $400 \mathrm{~Pa}$. A lower shear stress is possible but might cause large data fluctuation.

\section{Challenges}

During the measurement of rheological properties of cement pastes, there are a number of challenges to take into consideration, which could lead to wrong conclusions and invalid measurements [44]. In this section, the most commonly encountered challenges, and potential strategies to counter them, are addressed.

\subsection{Equilibrium conditions}

This challenge mainly applies on assessing flow curves of cement pastes. For thixotropic materials, there is an equilibrium structure at each shear rate $[2-4,45]$. If no equilibrium is achieved at each shear rate, the stress can be under- or over-estimated, leading to potential incorrect assessment of non-linearity of the flow curve $[9,32,46]$. This challenge may be overcome in two ways: either equilibrium is awaited for at each shear rate (supposing a stepwise measurement) [45], or equilibrium is awaited for at the largest shear rate during the measurement [32]. The first method requires a substantially longer measuring time during which the properties can change due to hydration. The second method corresponds to imposing a reference state, corresponding to the highest shear rate [32]. Once the reference state is achieved, the measurement of the flow curve is executed quickly, limiting the impact of the buildup caused by flocculation and hydration. Hence, a majority of the measurement procedures reported in literature impose a pre-shear period at the highest desired shear rate, which is typically in the order of $10^{1}-10^{2} \mathrm{~s}^{-1}$.

\subsection{Gap width}

In order to assure uniform shearing, the gap width should be small $\left(R_{i} / R_{o} \sim 0.99\right)$. The largest cement particles (ca. $\left.100 \mu \mathrm{m}\right)$ tempt to get blocked between typically small gaps and disturb the homogeneous laminar flow. Often a compromise is made by setting the gap width to approximately the tenfold of the maximum particle diameter under study, reducing the accuracy of the narrow gap equations. Nonuniformity can be anticipated by testing the geometry, the measuring protocol and the calculations can be evaluated with a particle suspension of known viscosity and, if possible, 
by visual verification. Alternatively, the maximum particle diameter can be lowered but this is often undesirable.

\subsection{Plug flow}

Plug flow corresponds to a situation where the sample in the rheometer is not entirely sheared, reducing the size of the sheared domain, requiring an adjusted calculation of the rheological properties [24,44]. This situation occurs only in concentric cylinder geometries, not in parallel plate configurations. Based on an initial value of the yield stress, the shear stress at the outer cylinder at the lowest rotational velocity can be calculated as: $\tau_{R o}=T / 2 \pi R_{o}{ }^{2} L$. Only if this stress is lower than the yield stress, iterative calculations are needed for all points in plug flow, by replacing $R_{0}$ with $R_{p}=$ $V\left(T / 2 \pi \tau_{0} L\right)$, and recalculating the rheological parameters. An alternative solution is to calculate the shear rate utilizing equations for an infinite gap rheometer [47]. Observing plug flow experimentally is difficult unless the fresh paste is really stiff so that the plug can be seen after the experiment. For concrete, some work has been done such as MRI on suspensions [48] and visualizing flow on the upper surface of a concentric viscometer with white powder on the fresh, rotating surface to facilitate observation [49]. If the yield stress is larger than $10^{3} \mathrm{~Pa}$ [50], viscosity cannot be accurately characterized and other tools and strategies are required to obtain reliable rheological properties [10-12].

\subsection{Transformation equations}

Most rheometers register torque and deflection angle as a function of time as data. Any other parameter is usually automatically calculated by the rheometer, based on transformation equations in the software typically in the shape of "shear rate = constant $x$ velocity". As shown above, the calculation of shear rate in concentric cylinders and the calculation of shear stress in parallel plates are not straightforward. Hence, this simple transformation is not fully accurate. One can employ the rheology textbook equations [13], but will encounter difficulties when assessing " $n$ " (see Eqs. 3 and 5). Integration procedures (e.g. ReinerRiwlin), transforming best-fitting curve parameters (e.g. intercept with T-axis and slope) into rheological parameters (yield stress and viscosity), instead of a point-to-point transformation of $T$ to shear stress and velocity to shear rate, are also used [44, 47, 51-53]. For static yield stress measurements, one can simply calculate the stress as $\tau_{0}=T$ / $2 \pi R_{i}^{2} L$ in coaxial cylinders, as only a very small portion of the sample is sheared. For visco-elastic measurements, if the raw torque and strain sine curves cannot be registered, insecurity concerning the rheometer calculations must be considered.

\subsection{Slip, particle migration and segregation}

Slip and shear-induced particle migration are perhaps the most difficult challenges to evaluate, except if an assessment of the velocity profile can be made independently [48, 54]. Although particle migration is more prominent in concrete mixtures, it cannot be excluded for cement pastes. Migration causes a depletion of particles in the zones with the highest shear rates, which is the inner cylinder radius in coaxial cylinders, and the edge of the plates in parallel plate rheometers [55]. On top of this, slip can occur when the friction between the plate and the sample is insufficient to overcome the applied stresses. As a result, a layer with less particles is created, invalidating the measurements. Typical strategies to avoid slip and particle migration are to apply appropriate roughness to the measuring geometry: i.e. serrated surfaces, sandblasted surfaces, or sandpaper on surfaces [21]. A vane geometry can be considered an extreme case of a serrated inner cylinder. A second strategy is to perform the measurement as quickly as feasible, as particle migration needs time to progress. Reducing the maximum applied shear rate is also helpful to limit slip or particle migration during measurements. Segregation or bleeding can be another challenge, as it changes the particle volume fraction over the height of the specimen with time, especially for extended measurements on the same sample [17].

\subsection{Mixing}

The effect of the sample shear history on the rheological measurements must also be considered. Intensive shearing in the mixer will impose the reference state due to mixing. Less intensive mixers allow for imposing the reference state during the first measurement in the rheometer [56]. It is important to note that the mixing intensity of the paste will also have a pronounced effect on the correlation of the rheological properties of the cement paste prepared separately to the properties of the paste mixed as part of the concrete.

\section{Summary}

When cement researchers use rheometers, they should know that their result will depend on their choice of protocol and tested material. This technical letter lists some of the most frequent choices that researchers can make in the field of cement paste rheometry. Unfortunately, there is no single procedure that works for all rheometers and there is no rheometer setting that works for all materials. If no standard geometry is used, one can compare measurements from the same device, but difficulties arise to derive the correct rheological properties of the paste, and relating the results with values from other researchers is not straightforward. On the other hand, even when applying a standardized geometry, there is no guarantee that the measured rheological properties are correct. A number of measuring artefacts can occur which may compromise the measurements. Therefore, it is recommended to consider as many concerns as possible listed in this technical letter and in literature.

\section{References}

[1] R. Shaughnessy, P.E. Clark, The rheological behaviour of fresh cement pastes. Cem Conc Res (1988) 18: 327-341. https://doi.org/10.1016/0008-8846(88)90067-1 
[2] G.H. Tattersall, P.F. Banfill, The rheology of fresh concrete. London: Pitman, (1983)

[3] N. Roussel, A. Lemaître, R.J. Flatt, P. Coussot, Steady state flow of cement suspensions: a micromechanical state of the art. Cem Conc Res (2010) 40: 77-84. https://doi.org/10.1016/j.cemconres.2009.08.026

[4] J.E. Wallevik, Rheological properties of cement paste: thixotropic behaviour and structural breakdown. Cem Conc Res (2009) 39: 1429. https://doi.org/10.1016/j.cemconres.2008.10.001

[5] L.J. Struble, W.G. Lei, Rheological changes associated with setting of cement paste. Adv Cem Based Mat (1995) 2: 224-230. https://doi.org/10.1016/1065-7355(95)90041-1

[6] R.J. Flatt, I. Schober, Superplasticizers and rheology of concrete, in: Roussel, N. ed., Understanding the rheology of concrete, Woodhead Publishing Limited, Cambridge (2012). https://doi.org/10.1533/9780857095282.2.144

[7] M. Cyr, C. Legrand, M. Mouret, Study of the shear thickening effect of superplasticizers on the rheological behaviour of cement pastes containing or not mineral additives. Cem Conc Res (2000) 30: 14771483. https://doi.org/10.1016/S0008-8846(00)00330-6

[8] A. Yahia, K.H. Khayat, Analytical models for estimating yield stress of high-performance pseudoplastic grout. Cem Conc Res (2001) 31: 731-738. https://doi.org/10.1016/S0008-8846(01)00476-8

[9] D. Feys, R. Verhoeven, G. De Schutter, Why is fresh self-compacting concrete shear thickening? Cem Conc Res (2009) 39: 510-523. https://doi.org/10.1016/j.cemconres.2009.03.004

[10] Z. Toutou, N. Roussel, C. Lanos, The squeezing test: a tool to identify firm cement-based material's rheological behaviour and evaluate their extrusion ability. Cem Conc Res (2005) 35: 18911899. https://doi.org/10.1016/j.cemconres.2004.09.007

[11] A. Perrot, Y. Mélinge, D. Rangeard, F. Micaelli, P. Estellé, C. Lanos, Use of ram extruder as a combined rheo-tribometer to study the behaviour of high yield stress fluids at low strain rate. Rheol Acta (2012) 51: 743-754. https://doi.org/10.1007/s00397-012-0638-6

[12] A. Perrot, D. Rangeard, A. Pierre, A. Structural built-up of cementbased materials used for 3D-printing extrusion techniques. Mater Struct (2016) 49: 1213-1220. https://doi.org/10.1617/s11527-015-0571-0

[13] C.W. Macosko, Rheology: principles, measurements, and applications. Wiley-vch (1994).

[14] P. Coussot, Rheometry of pastes, suspensions, and granular materials: applications in industry and environment. John Wiley \& Sons, Inc., New Jersey (2005). https://doi.org/10.1002/0471720577

[15] G. Ovarlez, Introduction of the Rheometry of complex suspensions, in: Roussel, N. ed., Understanding the rheology of concrete, Woodhead Publishing Limited, Cambridge (2012). https://doi.org/10.1533/9780857095282

[16] T.G. Mezger, The Rheology Handbook, $2^{\text {nd }}$ Edition, Vincentz Network GmbH \& Co. KG, Hannover (2006).

[17] Q.G. Hoang, A. Kaci, E.H. Kadri, J.L. Gallias, J.L., A new methodology for characterizing segregation of cement grouts during rheological tests. Constr Build Mater (2015) 96: 119-126. https://doi.org/10.1016/j.conbuildmat.2015.08.008

[18] C.F. Ferraris, N.S. Martys, W.L. George, Development of standard reference materials for rheological measurements of cementbased materials. Cem Conc Comp (2014) 54: 29-33. https://doi.org/10.1016/j.cemconcomp.2014.01.008

[19] H.A. Barnes, Q.D. Nguyen, Rotating vane rheometry-a review. J Non-Newton Fluid (2001) 98: 1-14.

[20] H.A. Barnes, J.O. Carnali, The vane-in-cup as a novel rheometer geometry for shear thinning and thixotropic materials. J Rheol (1990) 34: 841-866. https://doi.org/10.1122/1.550103

[21] C.F. Ferraris, Measurement of the rheological properties of cement paste: a new approach. In Int. RILEM Conf. The role of admixtures in high performance concrete (1999): 333-342.

[22] F.A. Cardoso, A.L. Fujii, R.G. Pileggi, M. Chaouche, Parallel-plate rotational rheometry of cement paste: Influence of the squeeze velocity during gap positioning. Cem Conc Res (2015) 75: 66-74. https://doi.org/10.1016/i.cemconres.2015.04.010

[23] X. Chateau, G. Ovarlez, K.L. Trung, Homogenization approach to the behaviour of suspensions of noncolloidal particles in yield stress fluids. J Rheol (2008) 52: 489-506. https://doi.org/10.1122/1.2838254

[24] J.E. Wallevik, Rheology of particle suspensions: fresh concrete, mortar and cement paste with various types of lignosulfonates. Doctoral thesis, The Norwegian University of Science and Technology (NTNU) (2003).
[25] P.F.G. Banfill, D.C. Saunders, On the viscometric examination of cement pastes. Cem Conc Res (1981) 11: 363-370. https://doi.org/10.1016/0008-8846(81)90108-3

[26] R. Lapasin, A. Papo, S. Rajgelj, Flow behaviour of fresh cement pastes. A comparison of different rheological instruments and techniques. Cem Conc Res (1983) 13: 349-356. https://doi.org/10.1016/0008-8846(83)90034-0

[27] A. Papo, Rheological models for cement pastes. Mater Struct (1988) 21: 41-46. https://doi.org/10.1007/BF02472527

[28] C. Atzeni, L. Massidda, U. Sanna, Comparison between rheological models for portland cement pastes. Cem Conc Res (1985) 15: 511519. https://doi.org/10.1016/0008-8846(85)90125-5

[29] A. Yahia, K.H. Khayat, Applicability of rheological models to highperformance grouts containing supplementary cementitious materials and viscosity enhancing admixture. Mater Struct (2003) 36: 402-412. https://doi.org/10.1007/BF02481066

[30] P. Billberg, Form pressure generated by self-compacting concrete: influence of thixotropy and structural behaviour at rest. Doctoral thesis, School of Architecture and the Built Environment, Division of Concrete Structures, Royal Institute of Technology, Stockholm, Sweden (2006).

[31] N. Roussel, G. Ovarlez, S. Garrault, C. Brumaud, The origins of thixotropy of fresh cement pastes. Cem Conc Res (2012) 42: 148157. https://doi.org/10.1016/j.cemconres.2011.09.004

[32] N. Roussel, A thixotropy model for fresh fluid concretes: theory, validation and applications. Cem Conc Res (2006) 36: 1797-1806. https://doi.org/10.1016/j.cemconres.2006.05.025

[33] V. Petkova, V. Samichkov, Some influences on the thixotropy of composite slag Portland cement suspensions with secondary industrial waste. Constr Build Mater (2007) 21: 1520-1527. https://doi.org/10.1016/j.conbuildmat.2006.04.011

[34] R.P. Ferron, A. Gregori, Z. Sun, S.P. Shah, Rheological method to evaluate structural buildup in self-consolidating concrete cement pastes. ACI Mat J (2007) 104: 242.

[35] J. Mewis, N.J. Wagner, Thixotropy. Adv Colloid Interfac (2009) 147: 214-227. https://doi.org/10.1016/j.cis.2008.09.005

[36] H.A. Barnes, Thixotropy-a review. J. Non-Newton. Fluid (1997) 70: 1-33.

[37] Q. Yuan, D. Zhou, K.H. Khayat, D. Feys, C. Shi, On the measurement of evolution of structural build-up of cement paste with time by static yield stress test vs. small amplitude oscillatory shear test. Cem Conc Res (2017) 99: 183-189. https://doi.org/10.1016/j.cemconres.2017.05.014

[38] A. Papo, B. Caufin, A study of the hydration process of cement pastes by means of oscillatory rheological techniques. Cem Conc Res (1991) 21: 1111-1117. https://doi.org/10.1016/0008-8846(91)90071-0

[39] L.J. Struble, M.A. Schultz, Using creep and recovery to study flow behaviour of fresh cement paste. Cem Conc Res (1993) 23: 13691379. https://doi.org/10.1016/0008-8846(93)90074-J

[40] T. Conte, M. Chaouche, Rheological behaviour of cement pastes under Large Amplitude Oscillatory Shear. Cem Conc Res (2016) 89: 332-344. https://doi.org/10.1016/j.cemconres.2016.07.014

[41] Z. Sun, T. Voigt, S.P. Shah, Rheometric and ultrasonic investigations of viscoelastic properties of fresh Portland cement pastes. Cem Conc Res (2006) 36: 278-287. https://doi.org/10.1016/j.cemconres.2005.08.007

[42] M.A. Schultz, L.J. Struble, Use of oscillatory shear to study flow behaviour of fresh cement paste. Cem Conc Res (1993) 23: 273282. https://doi.org/10.1016/0008-8846(93)90092-N

[43] N. Roussel, A. Lemaître, R.J. Flatt, P. Coussot, Steady state flow of cement suspensions: a micromechanical state of the art. Cem Conc Res (2010) 40: 77-84. https://doi.org/10.1016/j.cemconres.2009.08.026

[44] O.H. Wallevik, D. Feys, J.E. Wallevik, K.H. Khayat, Avoiding inaccurate interpretations of rheological measurements for cement-based materials. Cem Conc Res (2015) 78: 100-109. https://doi.org/10.1016/j.cemconres.2015.05.003

[45] D.H. Cheng, Hysteresis loop experiments and the determination of thixotropic properties. Nature (1967) 216: 1099-1100. https://doi.org/10.1038/2161099a0

[46] M.R. Geiker, M. Brandl, L.N. Thrane, D.H. Bager, O. Wallevik, The effect of measuring procedure on the apparent rheological properties of self-compacting concrete. Cem Conc Res (2002) 32: 1791-1795. https://doi.org/10.1016/S0008-8846(02)00869-4 
[47] P. Estellé, C. Lanos, A. Perrot, Processing the Couette viscometry data using a Bingham approximation in shear rate calculation. J. Non-Newton. Fluid (2008) 154: 31-38.

[48] H. Hafid, G. Ovarlez, F. Toussaint, P.H. Jézequel, N. Roussel, Estimating measurement artifacts in concrete rheometers from MRI measurement on model materials. In Design, Production and Placement of Self-Consolidating Concrete, (2010): 127-137. https://doi.org/10.1007/978-90-481-9664-7 11

[49] S. Jacobsen, H. Vikan, L. Haugan, Flow of SCC along surfaces. In Design, Production and Placement of Self-Consolidating Concrete, (2010): 163-173. https://doi.org/10.1007/978-90-481-9664-7 14

[50] A. Pierre, A. Perrot, A. Histace, S. Gharsalli, E.H. Kadri, A study on the limitations of a vane rheometer for mineral suspensions using image processing. Rheol Acta (2017) 56: 351-367. https://doi.org/10.1007/s00397-017-0993-4

[51] M. Reiner, Deformation and Flow; An Elementary Introduction to Theoretical Rheology. H. K. Lewis \& Co. Limited, (1949).

[52] G. Heirman, L. Vandewalle, D. Van Gemert, O. Wallevik, Integration approach of the Couette inverse problem of powder type selfcompacting concrete in a wide-gap concentric cylinder rheometer. J. Non-Newton. Fluid (2008) 150: 93-103.

https://doi.org/10.1016/j.jnnfm.2007.10.003

[53] D. Feys, J.E. Wallevik, A. Yahia, K.H. Khayat, O.H. Wallevik, Extension of the Reiner-Riwlin equation to determine modified Bingham parameters measured in coaxial cylinders rheometers. Mater Struct (2013) 46: 289-311.

https://doi.org/10.1617/s11527-012-9902-6

[54] S. Jarny, N. Roussel, S. Rodts, F. Bertrand, R. Le Roy, P. Coussot, Rheological behaviour of cement pastes from MRI velocimetry. Cem Conc Res (2005) 35: 1873-1881.

https://doi.org/10.1016/j.cemconres.2005.03.009

[55] D. Leighton, A. Acrivos, The shear-induced migration of particles in concentrated suspensions. J Fluid Mech (1987) 181: 415-439. https://doi.org/10.1017/S0022112087002155

[56] D. Han, R.D. Ferron, Effect of mixing method on microstructure and rheology of cement paste. Constr Build Mater (2015) 93: 278-288. https://doi.org/10.1016/j.conbuildmat.2015.05.124 